\title{
Analysis of advantages of gold (Au) wash solution for chemical analysis of soil and water samples in Sundarbans by IPC-MS
}

\author{
Awal Mohd Abdul \\ Environmental Scientist, Ministry of Environment \& Forests (MOEF), and Founder \& Chief Advisor, Health \& Pollution Research Farm, \\ Bangladesh, Present Address: 23-09-37 Avenue, Apt, No: 1, Long Island City, New York, USA
}

\section{Email address:}

abdul_awal2004@yahoo.com

\section{To cite this article:}

Awal Mohd Abdul. Analysis of Advantages of Gold (Au) Wash Solution for Chemical Analysis of Soil and Water Samples in Sundarbans by IPC-MS. American Journal of Biomedical and Life Sciences. Vol. 2, No. 5, 2014, pp. 108-118. doi: 10.11648/j.ajbls.20140205.12

\begin{abstract}
The Sundarbans is the largest, biologically richest, and most extensive mangrove forest in the world. Heritiera fomes (Sundri) tree is the most important ecologically dominant and economically valuable tree species in the Sundarbans. However, a serious disease (top dying) of $H$. fomes in Sundarbans is affecting millions of the trees. The loss of $H$. fomes will have a major impact on the Sundarbans mangrove ecosystem, as well as lead to economic losses. Despite various hypotheses as to the causes of this top-dying, the underlying causes are still not well understood. The present work has explored some of the possible factors involved, focusing particularly on the relationship between the amount of top-dying in different places and the concentrations of a number of chemical elements present in the soil and water, in order to test the hypothesis that chemical pollution might be responsible. Nine plots were selected for sampling of soil, water, and vegetation in order to categorize different areas in terms of their intensity of top-dying. 63 soil samples and 9 water samples were tested, mainly by ICPMS, to investigate certain parameters of the soil and water, such as $\mathrm{Sn}$, Exchangeable $\mathrm{K}$, Soil pH, $\mathrm{Pb}, \mathrm{Zn}, \mathrm{Ni}$, soil $\mathrm{pH}, \mathrm{CEC}$, soil nutrients, soil moisture content, and elemental concentrations of 32 other elements. Most of the elements studied had no significant correlation with the top dying of Heritiera fomes. However, $\mathrm{Sn}$, Exchangeable $\mathrm{K}$, and soil $\mathrm{pH}$ were significantly related, and three elements, namely $\mathrm{Pb}, \mathrm{Zn}, \mathrm{Ni}$, were also close to significance. Sn concentration is negatively associated with top dying. Soil $\mathrm{pH}$ varied significantly in the different plots. Exchangeable $\mathrm{K}$ was positively associated with the tree diameter whether the top dying was severe or mild. Of the hypotheses previously put forward to explain top-dying, the present results do not support enhanced salinity as the cause. It is likely that several of the above-mentioned environmental factors interact with each other to induce top dying in Sundri. However, the present results have showed that $\mathrm{Sn}$, Exchangeable $\mathrm{K}$, soil $\mathrm{pH}, \mathrm{Pb}, \mathrm{Zn}$ and $\mathrm{Ni}$ could be directly linked with top-dying of Heritiera fomes (Sundri) in Sundarbans, probably particularly by weakening the vigor of the trees and allowing other factors such as pathological agents to attack the plants.
\end{abstract}

Keywords: Chemical Analyses, Gold Wash Solution, Causal Factors, Heavy Metal Concentrations, Heritiera Fomes, Mangrove, Sundarbans, Top-Dying

\section{Introduction}

Coastal lands cover $6 \%$ of the world's land surface (Tiner, 1984). Coastal and wetlands everywhere are under threat from agricultural intensification, heavy metals' contaminations, environmental pollutions, major engineering schemes and urban developments (Awal, 2007, 2009, 2014; UN-ESCAP, 1987; 1988). 


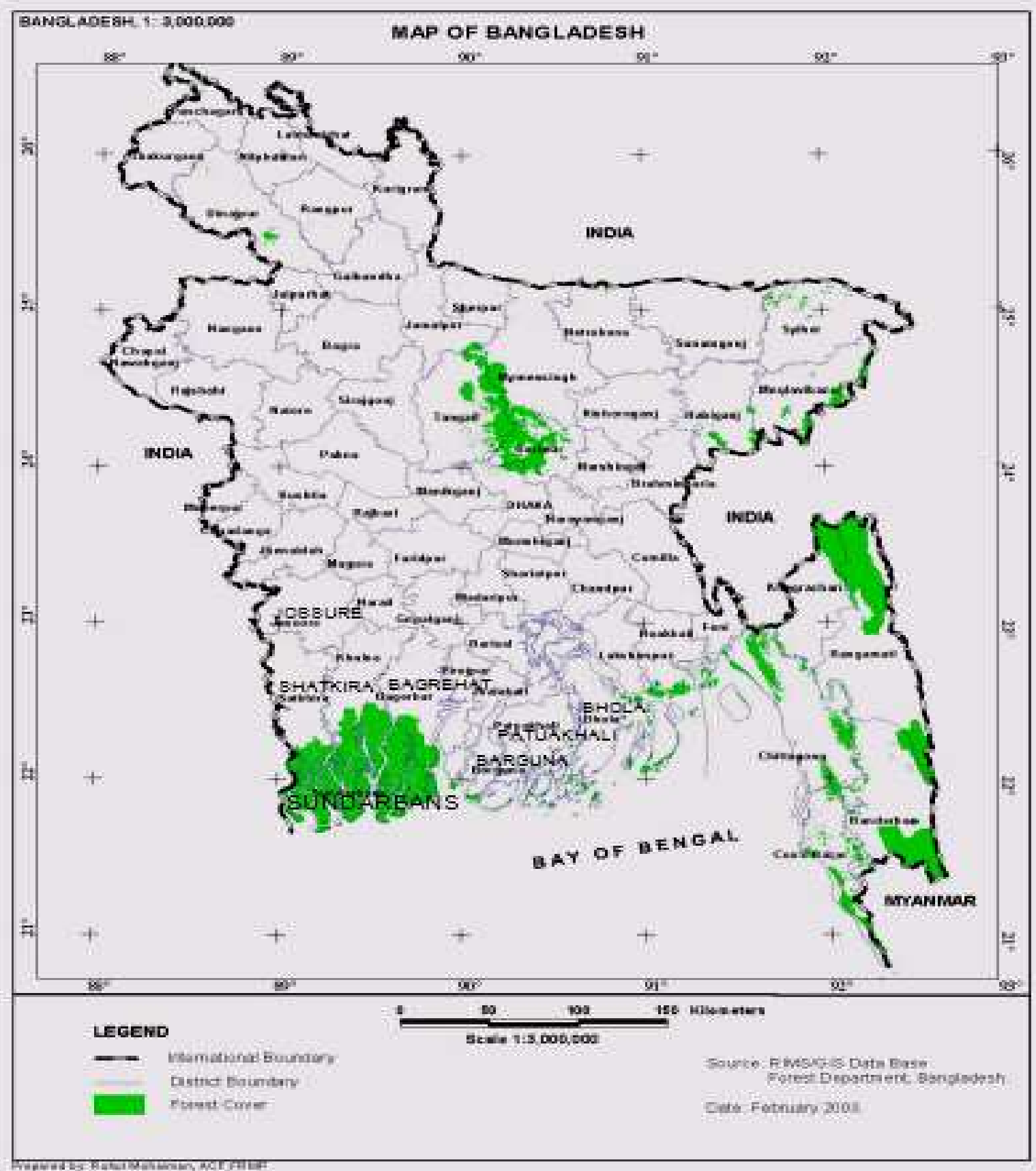

Figure 1.1. Map showing the administrative districts of Bangladesh, including the location of the Sundarbans (the shaded area in the south-west of the country).

The Indo-Pacific region is known for its luxuriant mangroves. Some earlier estimates of the distribution of mangroves include Bangladesh (Government of India, 1990). The distribution of mangroves in the Indo-West Pacific biogeographical region is outlined in Macnae (1968). The mangrove zone of Bangladesh is about $710 \mathrm{~km}$ long including several tiny islands (Rahman, et al., 2003). In the present day the Indo-Malayan mangroves are confined to Sundarban reserved forests, mainly in Bangladesh. According to Miller et al., $(1985,1981)$, this forest had been affected by human settlement and agricultural activities during and under both the Bengal Sultanate (1204-1575) and the Mughal Empire (1575-1765). At the arrival of British rule in 1765, the Sundarbans forests were double their present size and significant exhaustion of the growing stock led to dwindling by $40 \%-45 \%$ between 1959 and 1983 (Chaffey et al., 1985). Representing 2.5 percent of the world's mangrove forest (Saha, 1991), the Sundarban forest is still the largest natural single tract of mangrove forest and habitats in the world (Christensen, 1984; Seidensticker and 
Hai, 1983; Hussain and Karim, 1994) with 10, $029 \mathrm{~km}^{2}$ area. The total area of the part of Sundarban in Bangladesh is now about 6,017 km² (Imam, 1982; Christensen, 1984; Chaffey et al., 1985), which arose due to the eastward shift of the Ganges (Blasco, 1977; Naskar 1999; and Bakshi, 1954;
Thom, 1982). Heritiera fomes (Sundri) is the predominant tree species, supporting about $65 \%$ of the total merchantable timber (Chaffey et al., 1985, and Siddiqi, 2001).

\subsection{Location}

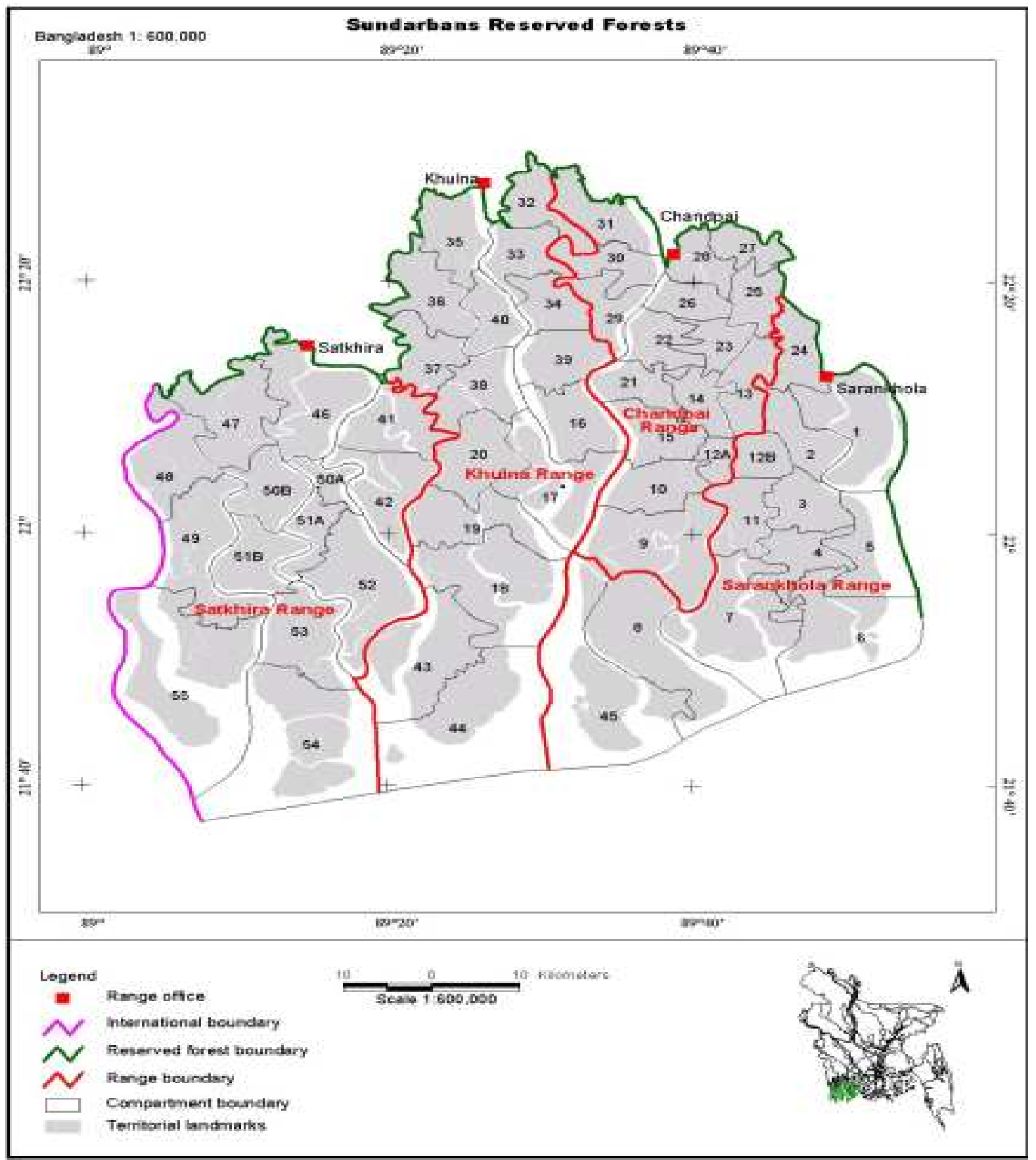

Figure 1.2. Shows compartment numbers and Ranges of Sundarbans Reserved Forest.

The Sundarban mangrove forest is located mainly at the southern portion of the Gangetic delta bordering on the Bay of Bengal (Blasco, 1977; Naskar 1999; and Bakshi, 1954; Thom, 1982), of Bangladesh (Figure1.1). It occupies a flat deltaic swamp rarely exceeding 0.9 to $2.1 \mathrm{~m}$ above the sea level and most of the area is under water during the high spring tides of the monsoon and the major portion of land is a low plain with maximum $10 \mathrm{~m}$ height above mean sea level (FAO, 1994). Sundarbans is subdivided into 8 blocks (Figure 1.2 ), and further subdivided into 55 compartments (Rahman, 2003) varying in size from 4000-16,000 ha (Tamang, 1993), depending on the height classes \& stocking conditions of the forest trees. The forest lies just south of the topic between $21^{\circ} 38^{\prime}-22^{\circ} 30^{\prime}$ North latitudes and $89^{\circ} 0^{\prime}-90^{\circ} 0^{\prime}$ East 
longitudes. Within the total areas of the Sundarbans, Heritiera fomes constituted $63.8 \%$ among the total tree vegetation (Chaffey et al., 1985).

\subsection{Soil}

The soils of the Ganges delta are unripened, slightly calcareous, tidally flooded, grey, massive, alkaline, clayey muds with low $(<2 \%)$ organic matter content (Anon, 1975; Hassan, 1988), although localized depressions may contain a higher amount $(>50 \%)$ of organic matter (Anon, 1975). The Sundarbans soils are rich in clay and silt content, and have been derived allochthonously from deltaic floodplain alluviums and autochthonously from tidal marsh materials consisting mainly of organic matter (peat deposition) and, to a lesser extent, from bicarbonates from shell-farming marine / estuarine organisms (Choudhury, 1962). Large amount of weather able minerals such as chemical elements, carbonates, and feldspars, are present in the silt fraction of these soils, which protect them from turning into acid sulphate conditions after drainage improvement (Anon, 1975). Moreover, the high clay content, high CEC and high $\mathrm{pH}$ of these soils are indicative of their potential fertility with the $\mathrm{pH}$ averaging 8.0 (Christensen, 1984). The Sundarban soil is classified as Typic Haplaquents (Anon, 1975; Gopalswamy and Chowdhury, 1973). In the eastern part of Sundarbans the surface soil is soft and fertile, whereas it is harder and less suitable for tree growth in the west (Choudhury, 1968).

The top soil horizon consists of silt and clay loam over alternating horizons of clay and sand (Choudhury, 1962). The surface is clay except on the seaward side of islands in the coastal limits, where sandy beaches occur. Alluvial deposits were geologically very recent and those were deep, poorly drained, fine textured, and had mineral compositions which were traceable to the bed rock parent-material of the gneissic mountains of the Himalayas. However, this surface soil was dominantly clay overlain with thin layers of silt delivered annually by monsoon floods. In the more eastern Sundarbans, where the silting process provided fertile nutrients, the delta forests are more highly productive and compacted, de-watered clays which tend to selectively concentrate chlorine (Landsberg, 1997). The carbonate initially present in the sediment is lost rapidly due to lateral decalcification (Ponnamperuma, 1965). The moisture content of mangrove soils has been reported to vary from $43 \%$ to $196 \%$ by dry weight of the soil by Giglioli and King (1966, 1995), and a similar range of values has been reported for surface soil moisture content of about $28.6 \%$ to $43.3 \%$ by dry weight (Faizuddin, 2003).

In the natural process, land in the Sundarban is formed by the silting up of the interlocking creeks, forming islands that eventually connect and are permanently above the water level and become slightly acidic (Awal, 2007; Own observation, 1993 -1997 as Head of East Wildlife Sanctuary (HEWS) and Assistant Conservator of Forests (ACF) in Sundarbans, Bangladesh. As a result, soil fertility has declined, and many rivers have become moribund (Mitra, 1954). The Sundarbans is therefore a dynamic natural resource, which may be affected by changing chemical and physical properties of soils which could affect forest growth. Working in Indonesia, the physico-chemical factors of mangrove soil were investigated and the soil $\mathrm{pH}$, the carbonates of salt and the content of humus in mangrove soils were found to be very important for species association (Navalkar and Bharucha, 1949), and this might be expected to be the same in the Sundarbans. Nitrogen, phosphorus and sulphur concentrations in soil have also been found to affect mangrove zonation (Faizuddin, 2003).

\section{Method}

The following section includes in the method of field work in Sundarbans:

\subsection{Field Sampling Methods}

The Sundarbans Reserved Forest is located at the south west corner of the Ganges River Delta close to the Bay of Bengal, mainly on the sea-shore line, river banks, channels, and small creeks. The location of the Sundarbans within Bangladesh has been shown in Figure 1.1.

\subsection{Site Selection and Location of the Study Area}

General reconnaissance of possible sites was made by visiting all the possible regional areas before categorizing and selecting plots for sampling. It was decided to sample from the Chandpai area which is the mostly human accessible and ecologically polluted area. Three compartments from this regional area (range), namely numbers 26, 28 and 31, were selected because they were believed to represent a range of severity of top dying disease, based on relevant maps, documents, literature, consultations with forest professionals, and surrounding peoples. The location of these compartments within the Chandpai area, and the location of this area in the wider Sundarbans is shown in Figure 1.2. Among the three compartments, compartment number 26 was selected as an area highly affected by top-dying, where most of the trees were affected severely. Compartment 26 had pronounced human activities, and also in places is undergoing rapid housing development involving extensive construction activities due to the presence nearby of the Range HQ office in Chandpai. Compartment number 28 was selected as a moderately affected area. This compartment has various human activities including boat making grounds, football-playing grounds, and cattle-grazing fields, all types of major soil erosion, a moderate amount of construction activities and the presence of communities of fishermen. Compartment number 31 was chosen as being relatively little affected by top-dying disease. Of the three chosen compartments, the nearest compartment to Mongla port is compartment 31, with comparatively modest human activities, but which nonetheless involve clear-cutting of natural vegetation, replanting with other species rather than mangrove or other native species, all types of soil erosion, and construction activities present. 
Within each of the three compartments, detailed observations of the regeneration sampling of soil and water took place within three $20 \mathrm{~m} \times 20 \mathrm{~m}$ plots, chosen to reflect a range of top dying intensities (High, medium and Low).

\subsection{Sample Recording Methods in the Field}

Within each of the nine $20 \mathrm{~m} \times 20 \mathrm{~m}$ plots, each adult tree was assessed for three parameters. The diameter at $1 \mathrm{~m}$ height was recorded (in $\mathrm{cm}$ ) by using a tree diametermeasuring tape or slide calipers depending on girth. The tree height to the top of the crown was determined mainly by ocular estimation but some heights were checked by using Clinometers at a set distance of $20 \mathrm{~m}$ to test the accuracy of such ocular estimations. Finally, the status of the tree in respect of the amount of top-dying was assessed by using a four point qualitative scale of intensity, namely; not affected, little affected, moderately affected or highly affected by topdying. This was later expressed as a semi-quantitative or rank scale of 0 to 3 respectively, so that a median rank value could be calculated and used as an index of top-dying intensity in that plot. After that, the total number of seedlings (individuals of the tree species $<1 \mathrm{~m}$ tall), and saplings (young trees $>1 \mathrm{~m}$ tall with a diameter of trunk of $<10 \mathrm{~cm}$ ), were counted within the plots. Care was taken to ensure that trees, saplings and seedlings were not counted more than once or missed in the counting process. After recording, adult trees were marked with white chalk to segregate those marked trees from other trees, seedlings and saplings; red paints were applied to all seedlings and saplings as they were recorded.

\subsection{Soil and Water Sampling Methods}

As stated above, from the three selected compartments, a total of nine plots of $20 \mathrm{~m} \times 20 \mathrm{~m}$ were selected. From each of these plots, seven soil samples were collected; one from the centre of the plot, four (one each) from all the corners, and two from the middle sides of the plot. Therefore a total of 63 soil samples were taken. Also nine water samples were collected from nearby rivers, creeks or channels, one from the area of each of the sampled plots.

Soil samples were collected from $0-30 \mathrm{~cm}$ soil depth by using a stainless steel spatula and steel cylinder $(d=5.25 \mathrm{~cm})$, and all soil samples were kept in sealed plastic bags. Water samples were collected directly in pre-cleaned plasticcontainers. Marking and labelling was performed with a detailed description of the selected sampling site on both the soil-containing plastic bags and water containers, and preserved in portable coolers until arrival at the laboratory at Dhaka University for initial chemical analysis. This field sampling method followed the W.H.O, U.K, and E.P.A systems of standard laboratory and field sampling principles, rules and regulations.

The sampling was conducted in a randomized block design, in that a plot was sited within a particular top-dying intensity block, but the precise location of that plot was randomized so as not to bias the detailed data collection.
Thus in total nine plots were sampled, representing a range of top-dying intensities. Intensive field data collection was made among these nine selected plots. Observations were performed from observation towers during low and high tides, also traversing the forest floor and vegetation on foot, as well as using a speed boat, trawlers, country-boats, and a launch as required to gain access. All sampling was accompanied by Deputy Rangers, Foresters, and Forest guards armed with a rifle from the local office, Chandpai rang, Bangladesh Forest Department, to prevent a fatal attack by a Bengal tiger (Panthera tigris).

Fieldwork was performed in October, 2003 to March, 2004. Locations of sampling points were determined using a Global Positioning System with a precision of 5-10 m. For one typical plot, in compartment 31 , the altitude was recorded as $4.4 \mathrm{~m}$ above sea level.

\subsection{Remove Adhering Pollutants and Materials from Soil Samples}

First of all, adhering materials were removed with forceps, and all sample materials were dried at ambient temperature to avoid decay and developing fungi, and were disaggregated to pass a laboratory test sieve using a brush. Soil samples were ground by an acid proof Porcelain Mortar Pestle using a porcelain hammer. After making the soil into powder, samples were kept in water and air proof plastic bags with proper labelling by marker pens.

Further sample preparation was under taken before ICPMS analyses. $0.2 \mathrm{~g}$ of soil samples, as well as $0.2 \mathrm{~g}$ of estuarine sediment, and $0.2 \mathrm{~g}$ of peach leaf (same weight of soil sample) were weighed by an Analytical Balance and put into a Teflon plastic beaker with proper labelling again. Then $4 \mathrm{ml}$ of concentrated Nitric acid was added to each sample of soil, peach leaf, estuarine sediment, and blank sample. Fresh blank samples were made for each separate set of acid digestions. Soil samples were digested by Microwave Digestion System (MDS) before chemical analysis with ICPMS. In all steps of soil sample preparation and analysis, cleanliness was ensured strictly to avoid all types of contamination during laboratory work. All samples were kept in a cool room until they were used for analysis, as were all solutions of sample material, to retain the properties of the material.

\subsection{Microwave Sample Preparation for Digestion Methods}

Weighed soil samples as well as the reference materials of peach leaf (1564), and estuarine sediment (1646) were placed in Teflon beakers. Four $\mathrm{ml}$ of concentrated $\mathrm{HNO}_{3}$ solution was added to all samples including blank samples, and the wooden head and bottom of Teflon beakers were fitted tightly. Samples were allowed to predigest in the Teflon beaker within a gas chamber for a minimum of 12 minutes or until the reaction of volatile or easily oxidized materials had subsided before sealing and carrying out microwave heating. Each Advanced Composite Vessel (ACV) was fitted with one rupture membrane (RM) produced by the CEM company Ltd, for each sample. The pressure control 
cover was then fitted to one of the ACV, ensuring all components were securely fitted together. Before heating, plastic membranes were set on the top of the cap of plastic Teflon beakers. The microwave oven was then set to the required temperature and the sample solution was heated slowly until the sample was at $103^{\circ} \mathrm{C}$, maintaining 175 (PSI) pressures, until the sample was dry and turned into ash (12 minutes). The residues were collected by washing the Teflon beakers with distilled water to make $250 \mathrm{ml}$ volume, to be used for the filtration of the aqueous phase. After cooling, each sample was transferred into a $250 \mathrm{ml}$ volumetric flask, and the solutions were diluted up to the mark, with doubledistilled water obtained by filtering using Whatman Number $40(9 \mathrm{~cm})$ and Number $42(11 \mathrm{~cm})$ filters. After filtering and making up to volume in a $250 \mathrm{ml}$ volumetric flask, the solution was well mixed by shaking.

\subsection{Contamination avoidance methods}

Cleanness of instruments and glassware in the preparation of soil and water samples for chemical analysis was strictly maintained to avoid all types of contamination during chemical analysis. Instruments were cleaned with appropriate blanks before beginning every experiment.

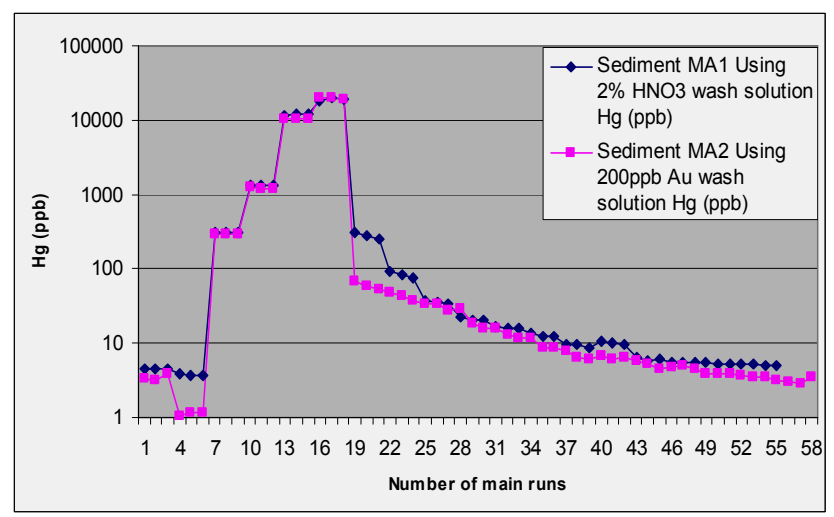

Figure 1.0. Output from ICP-MS analysis of $\mathrm{Hg}$.

All soil and water samples have been analyzed under a clean laboratory environment. Teflon coated beakers, funnels, Advanced Composite Vessel (ACV), plastic caps, volumetric flasks, beakers, pipettes and all other things were first washed by hot tap water, soapy water, cold water, then by deionised water or distilled water and finally with acid leached in deionised water. For drying, all these things were kept for 12 hours in an electrical heating or drying oven (Corsair Heating and Catering Ltd; UK). After use, they were washed again by this procedure before storing, to be washed again immediately prior to starting a new analysis.

The methodology used for the analysis of element concentrations by ICP-MS (Inductively Coupled PlasmaMass Spectrometry) needed to be developed in response to trial runs. The method actually used is described, together with the reasons for the choices made in reaching that method. The ICPMS was chosen as the instrumental procedure to be used because it is fast, and provides trace level, elemental analysis, for multi-element detection at limits below ng / 1 for solutions and ppb for solids. It can give a rapid turnover of samples (20-50 per day). Determinations were made for 63 soil samples, together with two reference materials (namely peach leaf; 1547, NIST, and estuarine sediment; 1646 NBS), and instrumental blanks freshly prepared for each set of materials analyzed. Thirty two elements were assessed, namely $\mathrm{Al}, \mathrm{As}, \mathrm{B}, \mathrm{Ba}, \mathrm{Bi}, \mathrm{Ca}$, $\mathrm{Cd}, \mathrm{Co}, \mathrm{Cr}, \mathrm{Cu}, \mathrm{Fe}, \mathrm{Hg}, \mathrm{In}, \mathrm{K}, \mathrm{Mg}, \mathrm{Mo}, \mathrm{Mn}, \mathrm{Na}, \mathrm{Ni}, \mathrm{P}, \mathrm{Pb}$, $\mathrm{Rb}, \mathrm{Sb}, \mathrm{Sc}, \mathrm{Se}, \mathrm{Si}, \mathrm{Sn}, \mathrm{Sr}, \mathrm{Ti}, \mathrm{V}, \mathrm{Y}$, and Zn.

After completing microwave digestion, all soil samples were taken into the University Analytical Centre for analysis. The instrument needs mass calibration standards for checking the detector response. Calibration standards need to be analyzed with each batch of samples. These should contain each of the elements of interest at different concentrations, with the internal standard. The addition of a known amount of internal standard to each and the weight/volume of digested sample allows full quantification of these elements. These standards are made from stock solutions, generally $1000 \mathrm{ppm}$ in $2 \%$ nitric acid $\left(\mathrm{HNO}_{3}\right)$. Instrument control is entirely run via a computer attached with ICPMS (Thermo Elemental Plasma Quard 3 ICP-MS; Serial No: MP11-002-204. Before analysis, the instrument was tuned to ensure that the ICP-MS would provide accurate data with high precision.

The instrument needs mass calibration standards for calibrating the detector response against concentration solutions. For five calibrations of $1 \mathrm{ppb}, 10 \mathrm{ppb}, 100 \mathrm{ppb}$, $200 \mathrm{ppb}$, and $1000 \mathrm{ppb}$ were prepared. For example, in the case of calibration No. 1, $0.1 \mathrm{ml}$ of solution was taken from the stock solutions (1000 ppb) and was diluted to $100 \mathrm{ml}$ and $2 \% \mathrm{HNO}_{3}$ was added, then filling up to the mark with deionised water. For calibration 2, the concentration of 10 ppb was obtained by using $0.01 \mathrm{ml}$ of standard, and diluting to $1000 \mathrm{ml}$ with deionised water. In the case of Calibration 3 , the desired concentration was $100 \mathrm{ppb}$ which was obtained from of $0.01 \mathrm{ml}$ of standard diluted to $100 \mathrm{ml}$ with deionised water. For Calibration 4, $200 \mathrm{ppb}$ was derived from $0.01 \mathrm{ml}$ of standard, diluted to $50 \mathrm{ml}$ with distilled water, and lastly for Calibration 5, $1000 \mathrm{ppb}$ involved $0.1 \mathrm{ml}$ of standard diluted to $100 \mathrm{ml}$ with distilled water. Each sample requires $10 \mathrm{ppb}$ Indium, added through $0.1 \mathrm{ml}$ plastic pipette to make the solution in volumetric flask before testing with ICP-MS. However, $\mathrm{Hg}$ was retained on the surfaces of the instrument. This is illustrated in Figure 1.0, which shows output from a single ICPMS run. The graph shows good consistency between replicates for the same test concentrations, but a steady decline in recorded values from run 19 onwards. This is indicative of retention and slow release of $\mathrm{Hg}$ within the instrument, which could lead to contamination of later results by earlier ones. In order to reduce this problem a gold wash solution (200 ppb) was subsequently used before taking the reading to get greater precision of results compared to the initial $\mathrm{HNO}_{3}$ wash solution (Figure 1.0). The results from this revised procedure were judged acceptable. After adding the gold-wash solution, the process of checking the 
calibration using the same procedure as before was repeated to ensure accurate readings. Due to the carryover of $\mathrm{Hg}$ from the concentrated calibrations (with both the standard $\mathrm{HNO}_{3}$ and $200 \mathrm{ppb}$ gold wash) it was decided to remake the

calibration solutions without $\mathrm{Hg}$. Therefore $\mathrm{Hg}$ is reported as semi-quantitatively only.

\section{Result}

Table 1.0. Data from chemical analysis of soil samples by ICP-MS for a range of chemical elements. Values are means $\pm 1 S$. E. (in ppb), in all cases being averages for seven samples from each plot in the three Compartments.

\begin{tabular}{lllll}
\hline Comp. No. & Plot No. & Sample Number. & Al (Aluminium) & As (Arsenic) \\
\hline 26 & 1 & $25,06,28,07,16,17,54$. & $21348.57 \pm 86.94$ & $30.04 \pm 0.07$ \\
26 & 2 & $15,42,30,03,49,08,14$. & $18207.14 \pm 131.33$ & $5.24 \pm 0.01$ \\
26 & 3 & $27,02,29,18,31,01,12$. & $16677.14 \pm 97.64$ & $4.72 \pm 0.10$ \\
28 & 1 & $39,32,43,52,38,63,04$. & $14351.71 \pm 66.31$ & $3.94 \pm 0.08$ \\
28 & 2 & $41,61,20,34,26,53,59$. & $15016.51 \pm 71.15$ & $4.040 \pm 0.12$ \\
28 & 3 & $48,45,35,11,46,58,55$. & $17500.00 \pm 69.99$ & $4.42 \pm 0.04$ \\
31 & 1 & $40,44,51,13,33,56,22$. & $15120.71 \pm 76.34$ & $5.00 \pm 0.07$ \\
31 & 2 & $47,50,36,57,24,62,37$. & $16390.66 \pm 126.99$ & $4.02 \pm 0.06$ \\
31 & 3 & $05,19,23,21,09,10,60$. & $14914.51 \pm 68.15$ & $4.07 \pm 0.31$ \\
\hline
\end{tabular}

Note: Samples numbers are the same of those in Table 1.0.

Table 2.0. Data from chemical analysis of soil samples by ICP-MS for a range of chemical elements. Values are means \pm 1 S. E. (in ppb), in all cases being averages for seven samples from each plot in the three Compartments

\begin{tabular}{lllll}
\hline Comp. No. & Plot No. & B (Boron) & Ba (Barium) & Bi (Bismuth) \\
\hline 26 & 1 & $19.63 \pm 0.24$ & $62.42 \pm 0.15$ & $0.51 \pm 0.01$ \\
26 & 2 & $22.70 \pm 0.22$ & $62.17 \pm 0.45$ & $0.51 \pm 0.01$ \\
26 & 3 & $14.11 \pm 0.23$ & $48.66 \pm 0.13$ & $0.45 \pm 0.01$ \\
28 & 1 & $28.72 \pm 0.37$ & $46.42 \pm 0.86$ & $0.35 \pm 0.01$ \\
28 & 2 & $15.47 \pm 0.22$ & $41.83 \pm 0.17$ & $0.32 \pm 0.04$ \\
28 & 3 & $26.84 \pm 0.29$ & $50.65 \pm 0.34$ & $0.30 \pm 0.03$ \\
31 & 1 & $13.74 \pm 0.30$ & $51.18 \pm 0.14$ & $0.37 \pm 0.01$ \\
31 & 2 & $17.23 \pm 0.28$ & $53.02 \pm 0.14$ & $0.33 \pm 0.01$ \\
31 & 3 & $15.14 \pm 2.95$ & $50.68 \pm 0.16$ & $0.39 \pm 0.01$ \\
\hline
\end{tabular}

Note: Samples numbers are the same of those in Table 2.0.

Table 3.0. Data from chemical analysis of soil samples by ICP-MS for a range of chemical elements. Values are means \pm 1 S. E. (in ppb), in all cases being averages for seven samples from each plot in the three Compartments

\begin{tabular}{llllll}
\hline Comp. No. & Plot No. & Cd (Cadmium) & Co (Cobalt) & Cr (Chromium) & Cu (Copper) \\
\hline 26 & 1 & $20.67 \pm 0.01$ & $13.41 \pm 0.07$ & $17.45 \pm 0.05$ & $8.37 \pm 0.02$ \\
26 & 2 & $31.30 \pm 0.01$ & $13.79 \pm 0.07$ & $18.73 \pm 0.09$ & $8.07 \pm 0.02$ \\
26 & 3 & $28.55 \pm 0.01$ & $19.53 \pm 0.04$ & $4.10 \pm 0.02$ & $3.41 \pm 0.02$ \\
28 & 1 & $18.07 \pm 0.08$ & $40.65 \pm 0.24$ & $12.20 \pm 0.07$ & $15.22 \pm 0.11$ \\
28 & 2 & $18.60 \pm 0.02$ & $28.34 \pm 0.01$ & $9.27 \pm 0.06$ & $7.93 \pm 0.03$ \\
28 & 3 & $16.82 \pm 0.03$ & $65.50 \pm 0.41$ & $31.99 \pm 0.22$ & $18.98 \pm 0.11$ \\
31 & 1 & $36.29 \pm 0.02$ & $55.22 \pm 0.29$ & $21.86 \pm 0.09$ & $16.77 \pm 0.05$ \\
31 & 2 & $35.40 \pm 0.02$ & $44.47 \pm 0.22$ & $20.29 \pm 0.07$ & $16.66 \pm 0.06$ \\
31 & 3 & $33.84 \pm 0.01$ & $13.84 \pm 0.58$ & $5.06 \pm 0.19$ & $4.40 \pm 0.24$ \\
\hline
\end{tabular}

Note: Samples numbers are the same of those in Table 3.0.

Table 4.0. Data from chemical analysis of soil samples by IPC-MS for a range of chemical elements. Values are means $\pm 1 S$. E. (in ppb), in all cases being averages for seven samples from each plot in the three Compartments.

\begin{tabular}{lllll}
\hline Comp. No. & Plot No. & Fe (Iron) & Hg (Mercury) & In (Indium) \\
\hline 26 & 1 & $208202.85 \pm 700.32$ & $6.57 \pm 0.44$ & $1.46 \pm 0.0$ \\
26 & 2 & $201175.71 \pm 943.55$ & $15.69 \pm 0.79$ & $1.42 \pm 0.0$ \\
26 & 3 & $206900.00 \pm 1064.13$ & $3.89 \pm 0.23$ & $1.53 \pm 0.0$ \\
28 & 1 & $148778.57 \pm 740.60$ & $8.72 \pm 0.12$ & $1.01 \pm 0.0$ \\
28 & 2 & $153415.11 \pm 542.14$ & $6.83 \pm 0.48$ & $0.96 \pm 0.0$ \\
28 & 3 & $114756.66 \pm 367.33$ & $4.77 \pm 0.26$ & $0.59 \pm 0.0$ \\
31 & 1 & $126872.85 \pm 680.00$ & $5.98 \pm 0.29$ & $0.02 \pm 0.0$ \\
31 & 2 & $144935.00 \pm 1134.95$ & $4.12 \pm 0.12$ & $0.94 \pm 0.0$ \\
31 & 3 & $183499.42 \pm 3483.11$ & $4.55 \pm 0.32$ & $2.53 \pm 0.3$ \\
\hline
\end{tabular}

Note: Samples numbers are the same of those in Table 4.0. 
Table 5.0. Data from chemical analysis of soil samples by ICP-MS for a range of chemical elements. Values are means $\pm 1 S$. E. (in ppb), in all cases being averages for seven samples from each plot in the three Compartments

\begin{tabular}{llll}
\hline Comp. No. & Plot No. & K (Potassium) & Mg (Magnesium) \\
\hline 26 & 1 & $4884.42 \pm 15.76$ & $10144.42 \pm 45.44$ \\
26 & 2 & $4065.71 \pm 21.08$ & $9554.43 \pm 55.69$ \\
26 & 3 & $3901.42 \pm 22.70$ & $8043.57 \pm 45.83$ \\
28 & 1 & $3402.28 \pm 15.37$ & $7238.00 \pm 39.26$ \\
28 & 2 & $3347.07 \pm 13.59$ & $7618.73 \pm 36.54$ \\
28 & 3 & $3909.83 \pm 17.17$ & $8326.33 \pm 30.10$ \\
31 & 1 & $3746.42 \pm 16.88$ & $9094.00 \pm 40.74$ \\
31 & 2 & $3821.66 \pm 22.87$ & 94.19 \\
31 & 3 & $3480.52 \pm 21.37$ & 9.19 \\
\hline
\end{tabular}

Note: Samples numbers are the same of those in Table 5.0.

Table 6.0. Data from chemical analysis of soil samples by ICP-MS for a range of chemical elements. Values are means $\pm 1 S$. E. (in ppb), in all cases being averages for seven samples from each plot in the three Compartments

\begin{tabular}{llll}
\hline Comp. No. & Plot No. & Mn (Manganese) & Na (Sodium) \\
\hline 26 & 1 & $470.45 \pm 1.69$ & $1612.85 \pm 6.2$ \\
26 & 2 & $463.72 \pm 2.19$ & $1971.57 \pm 9.4$ \\
26 & 3 & $454.75 \pm 2.26$ & $831.35 \pm 6.19$ \\
28 & 1 & $424.67 \pm 2.18$ & $986.55 \pm 5.78$ \\
28 & 2 & $308.82 \pm 1.49$ & $767.26 \pm 5.30$ \\
28 & 3 & $439.41 \pm 1.98$ & $1132.85 \pm 6.51$ \\
31 & 1 & $462.41 \pm 2.23$ & $2122.17 \pm 12.4$ \\
31 & 2 & $445.65 \pm 2.69$ & $2376.33 \pm 12.5$ \\
31 & 3 & $433.57 \pm 3.79$ & $1287.14 \pm 11.0$ \\
\hline
\end{tabular}

Note: Samples numbers are the same of those in Table 6.0.

Table 7.0. Data from chemical analysis of soil samples by ICP-MS for a range of chemical elements. Values are means $\pm 1 S$. E. (in ppb), in all cases being averages for seven samples from each plot in the three Compartments

\begin{tabular}{|c|c|c|c|c|}
\hline Comp. No. & Plot No. & P (Phosphorus) & $\mathrm{Pb}$ (Lead) & Rb (Rubidium) \\
\hline 26 & 1 & $844.67 \pm 3.94$ & $23.56 \pm 0.13$ & $43.97 \pm 0.09$ \\
\hline 26 & 2 & $803.22 \pm 3.73$ & $22.22 \pm 0.15$ & $40.51 \pm 0.10$ \\
\hline 26 & 3 & $982.61 \pm 5.82$ & $17.86 \pm 0.13$ & $30.83 \pm 0.15$ \\
\hline 28 & 1 & $614.32 \pm 2.90$ & $20.09 \pm 0.13$ & $28.71 \pm 0.15$ \\
\hline 28 & 2 & $658.58 \pm 2.19$ & $15.47 \pm 0.15$ & $33.68 \pm 0.06$ \\
\hline 28 & 3 & $397.09 \pm 1.87$ & $17.07 \pm 0.10$ & $35.00 \pm 0.10$ \\
\hline 31 & 2 & $602.24 \pm 4.18$ & $20.80 \pm 0.17$ & $36.68 \pm 0.21$ \\
\hline 31 & 3 & $802.68 \pm 2.88$ & $19.75 \pm 0.4$ & $33.22 \pm 0.89$ \\
\hline
\end{tabular}

Note: Samples numbers are the same of those in Table 7.0.

Table 8.0. Data from chemical analysis of soil samples by ICP-MS for a range of chemical elements. Values are means $\pm 1 S$. E. (in ppb), in all cases being averages for seven samples from each plot in the three Compartments

\begin{tabular}{|c|c|c|c|c|}
\hline Comp. No. & Plot No. & Sb (Antimony) & Sc (Scandinium) & Se (Selenium) \\
\hline 26 & 1 & (-) $0.14 \pm 0.00$ & $8.146 \pm 0.07$ & $0.13 \pm 0.22$ \\
\hline 26 & 2 & (-) $0.07 \pm 0.00$ & $7.349 \pm 0.08$ & (-) $0.44 \pm 0.21$ \\
\hline 26 & 3 & $(-) 0.09 \pm 0.00$ & $7.289 \pm 0.17$ & $(-) 1.69 \pm 0.36$ \\
\hline 28 & 1 & $0.007 \pm 0.008$ & $4.067 \pm 0.05$ & (-) $0.68 \pm 0.17$ \\
\hline 28 & 2 & $0.045 \pm 0.007$ & $6.390 \pm 0.08$ & $(-) 0.73 \pm 0.27$ \\
\hline 28 & 3 & $0.06 \pm 0.005$ & $3.290 \pm 0.03$ & $(-) 0.14 \pm 0.17$ \\
\hline 31 & 1 & $0.03 \pm 0.008$ & $4.856 \pm 0.07$ & (-) $0.41 \pm 0.15$ \\
\hline 31 & 2 & $0.459 \pm 0.02$ & $4.983 \pm 0.35$ & $(-) 0.67 \pm 0.21$ \\
\hline 31 & 3 & $0.08 \pm 0.007$ & $5.570 \pm 0.18$ & $(-) 1.05 \pm 0.28$ \\
\hline
\end{tabular}

Note: Samples numbers are the same of those in Table 8.0. 
Table 9.0. Data from chemical analysis of soil samples by ICP-MS for a range of chemical elements. Values are means \pm 1 S. E. (in ppb), in all cases being averages for seven samples from each plot in the three Compartments.

\begin{tabular}{lllll}
\hline Comp. No. & Plot No. & Si (Silicon) & Sn (Tin) & Sr (Strontium) \\
\hline 26 & 1 & $2870.32 \pm 11.27$ & $0.49 \pm 0.01$ & $30.20 \pm 0.09$ \\
26 & 2 & $2475.84 \pm 13.70$ & $0.67 \pm 0.01$ & $30.77 \pm 0.10$ \\
26 & 3 & $3159.42 \pm 19.27$ & $1.83 \pm 0.01$ & $26.08 \pm 0.15$ \\
28 & 1 & $2321.02 \pm 16.97$ & $0.17 \pm 0.03$ & $24.18 \pm 0.15$ \\
28 & 2 & $1959.81 \pm 10.43$ & $0.24 \pm 0.01$ & $21.38 \pm 0.06$ \\
28 & 3 & $1158.83 \pm 8.58$ & $0.79 \pm 0.009$ & $23.58 \pm 0.10$ \\
31 & 1 & $1455.00 \pm 12.36$ & $0.26 \pm 0.01$ & $29.38 \pm 0.15$ \\
31 & 2 & $1991.09 \pm 23.91$ & $0.26 \pm 0.03$ & $32.88 \pm 0.21$ \\
31 & 3 & $2650.42 \pm 14.43$ & $6.66 \pm 0.02$ & $30.05 \pm 0.89$ \\
\hline
\end{tabular}

Note: Samples numbers are the same of those in Table 9.0.

Table 10.0. Data from chemical analysis of soil samples by ICP-MS for a range of chemical elements. Values are means \pm 1 S. E. (in ppb), in all cases being averages for seven samples from each plot in the three Compartments

\begin{tabular}{llllll}
\hline Comp. No. & Plot No. & Ti (Titanium) & V (Vanadium) & Y Yttrium & Zn (Zinc) \\
\hline 26 & 1 & $579.9 \pm 2.17$ & $34.17 \pm 0.03$ & $7.73 \pm 0.01$ & $83.19 \pm 0.30$ \\
26 & 2 & $488.52 \pm 2.89$ & $36.18 \pm 0.18$ & $7.45 \pm 0.01$ & $81.76 \pm 0.29$ \\
26 & 3 & $422.82 \pm 2.63$ & $32.86 \pm 0.18$ & $5.52 \pm 0.03$ & $69.62 \pm 0.40$ \\
28 & 1 & $429.32 \pm 2.31$ & $30.44 \pm 0.15$ & $5.93 \pm 0.02$ & $77.25 \pm 0.37$ \\
28 & 2 & $497.74 \pm 1.71$ & $28.36 \pm 0.09$ & $6.07 \pm 0.02$ & $64.58 \pm 0.29$ \\
28 & 3 & $517.35 \pm 2.18$ & $26.55 \pm 0.15$ & $7.58 \pm 0.03$ & $80.33 \pm 0.33$ \\
31 & 1 & $458.10 \pm 2.56$ & $29.97 \pm 0.14$ & $6.68 \pm 0.03$ & $75.49 \pm 0.42$ \\
31 & 2 & $413.38 \pm 2.29$ & $31.17 \pm 0.18$ & $6.95 \pm 0.04$ & $69.76 \pm 0.40$ \\
31 & 3 & $445.27 \pm 7.39$ & $30.27 \pm 0.20$ & $5.60 \pm 0.24$ & $63.02 \pm 0.98$ \\
\hline
\end{tabular}

Note: Samples numbers are the same of those in Table 10.0.

\section{Discussion}

Values from the chemical analyses by ICPMS of the elemental composition of soils in the different compartments and plots are presented in a series of tables (1.0 to 10.0) owing to the large number of data values involved. This section will explore whether there is any significant variation in the values determined for each of the chemical components of the soils in relation to which plot and which compartment they were sampled from. In this section, therefore, the analyses have been carried out using a twofactor analysis of variance, where the compartment was one factor and the plot (selected according to perceived increasing top-dying intensity) was the second factor. It should be noted, however, that particularly the second factor was not controlled, since it is not possible to be certain that the relative intensity of top-dying of, for example, plot 2 in compartment 26 was equivalent to the relative top-dying intensity in plot 2 for compartment 31 . The interpretation of all results from the present analyses must therefore bear these points in mind. The nutrient concentrations included in Tables 1.0 to 10.0 . The fact that there is no significant difference between plots for any parameters (other than $\mathrm{pH}$ ) may be an indication that there is little variation in these parameters over the relatively small distances between plots; or the selection of plots based on top-dying has not selected for variation in these parameters because they are not correlated with the amount of top-dying.

The majority of elements did not show any significant pattern to the results, for compartment, plot or interaction. However, seven elements, Bi, Exchangeable K, P, Sc, Sr and $\mathrm{V}$, did show a significant difference between the three compartments, with compartment 26 having the greatest concentration of each of these elements and compartment 28 had the least. There were also a few other elements which showed results close to significance $(\mathrm{P}<0.10)$ which are also worth highlighting for further consideration, namely: $\mathrm{Sb}$ (plots were rather different); $\mathrm{Ca}$ (compartments showing variation); and in (both compartments and interactions were close to significance). With a large number of statistical tests, it is of course possible for occasional ones to be significant by chance; however, the proportion of tests which were significant or very close to it is higher than would be expected at random, and particularly with $\mathrm{Bi}$ and $\mathrm{V}$ the significance level was high, and therefore it can be started confidently that there are substantive variations in at least some of these chemical elements between different compartments and (with less confidence) some variations 
between plots. It is desirable to assess whether the chemical characteristics of soil or water have affected the growth of trees. However, none of the parameters tested showed a significant relationship with tree height, with exchangeable $\mathrm{Na}$ being the only element that even came close $(\mathrm{p}<0.10)$. Therefore, it does not appear that tree height is substantially affected by the parameters tested. It should be remembered that illicit felling of trees does occur in the areas studied, and it is possible that this extra factor might be influencing these results by selectively removing the largest trees, and making it more difficult for any correlation to be established.

The result for Sn has changed probability slightly, but sufficiently to become significant, while the result for $\mathrm{Pb}$ has moved to becoming less than $10 \%$ significance. All other results were clearly non-significant. Consequently it may be concluded that there is very little in terms of chemical parameters that shows any clear relationship with the amount of top-dying, with $\mathrm{Sn}$ and possibly $\mathrm{Pb}$ being the only elements with any notable effect. It may also be concluded that, while use of the quantitative Pearson's correlation coefficient slightly increases the significance of the results, it does not substantially change the conclusions that arose from using the rank correlation technique.

The heavy metal concentrations and other soil and water parameters tested in general did not show significant correlations with either the growth parameters for the trees or for the amount of top-dying as determined by the index of severity, although there were a few exceptions. However, there were significant differences between the compartments in a number of the parameters tested. The implications of these results, as well as those on vegetation structure and the questionnaire survey, will be discussed in the following chapter.

Values from the chemical analyses by ICPMS of the elemental composition of soils in the different compartments and plots are presented in a series of tables (1.0 to 10.0) owing to the large number of data values involved. It may also be concluded that, while use of the quantitative Pearson's correlation coefficient slightly increases the significance of the results, it does not substantially change the conclusions that arose from using the rank correlation technique.

The heavy metal concentrations and other soil and water parameters tested in general did not show significant correlations with either the growth parameters for the trees or for the amount of top-dying as determined by the index of severity, although there were a few exceptions. However, there were significant differences between the compartments in a number of the parameters tested.

\section{Conclusions}

Although there were only a few individual chemical elements which showed significant correlations with the amount of top-dying, there was evidence of elevated heavymetal concentrations of many elements in the Sundarbans, which are likely to contribute to the increase in top-dying observed. There were also significant differences between different areas in the Sundarbans, and evidence of water supply problems to the system. Therefore, it is concluded that several factors are responsible for this increase in topdying, rather than one specific factor only.

\section{Acknowledgements}

My research work was supported financially by the Peoples' Republic of Bangladesh and the Asian Development Bank (ADB), whom I thank. Particular thanks are due to the ADB head office, Manila for their support and help. I thank sincerely Dr. W.G.H. Hale (Principal Supervisor), University of Bradford, UK, Professor Mike Ashmore (Technical Supervisor), University of York, UK and Dr. P.J. Hogarth for their advice and comments on the work; Dr. Ben Stern and the staff at the Analytical Centre, Bradford, for their help with the ICPMS analyses; Professor Sirajul Hoque, Mustafa (lab Technician)and staff at Dhaka University for providing facilities; and staff of the Forestry Service, Bangladesh Government, for field assistance. Moreover I indebted to my beloved parents (Munshi Aowlad Hossain, Mrs. Ashrafunness), my wife (Dr. Shahanaj Khatun), my son (Munshi Tasneem Redowan), my daughter (Marwa Ashra), my beloved brothers (Munshi Abul Kalam Azad), and (Munshi Abdus Salam) and my 6 sisters (Layla Anjumand Banu (Chandu), Akter Rashida Banu (Turi), Saleha Pervin (Lili), Azmeri Ferdowsi (Dolly), Jannatul Ferdowsi (Polly) and my beloved youngest sister Bedowra Ferdowsi (Jolly), Oysorjo, Omeo, as well as all family members for their inspiration and help.

\section{References}

[1] Anonymous, 1975. Under-exploited tropical plants with promising economic value. National Academy of Sciences, Washington.

[2] Bakshi, B. K. 1954. Wilt disease of Dalbergia sissoo Roxb due to Fusarium solani Sensu Snyder and Hensen. Natural Nature 174: 278-291.

[3] Blasco, F. (1977). Outlines of Ecology, Botany and Forestry of the Mangals of the Indian sub-continent. In: Wet coastal ecosystem (ed. V.J. Chapman), Elsevier, Amsterdam 13(1), 19(2).

[4] Chaffey, D. R; Miller, F.R; Sandom, J. H. 1985. A forest inventory of the Sundarbans, Bangladesh, Main report, Project Report No.140, 196 pp; Overseas Development Administration, London, U.K:195-196.

[5] Chaudhury, A.M. (1962). Working Plan of Sundarbans Forest Division, for the period from 1960-61 to 1979-80, Vol I, II, and III. Forest Department.

[6] Chowdhury, J. H. 1973. Preliminary report of the investigation of the top dying of Sundri in the Sundarbans. BFRI, Chittagong, Bangladesh, 2 p.

[7] Chowdhury, A.M. 1968. Working Plan of Sundarbans Forest Division for the period from 1960-61 to 1961-80, 82 p. East Pakistan Government Press, Dacca. 
[8] Christensen, B. 1984. Integrated development of the Sundarbans, Bangladesh: Ecological aspects of the Sundarbans. Reported prepared for the Government of Bangladesh. FAO report no. FO: TCP/ BGD/2309(MF) W/ R0030.

[9] Faizuddin, M. 2003. Research on the Top Dying of Sundri in Bangladesh: 43, Mangrove Silviculture Division, Bangladesh Forest Research Institute, Khulna, Bangldesh.

[10] Faizuddin, M. and Islam, S.A. 2003. Generated Technology and Usable Information of the Mangrove Silviculture. Mangrove Silviculture Division, Bangladesh Forest Research Institute, Khulna, p. 17.

[11] FAO, 1994. Review of the state of world marine fisheries resources. FAO Fisheries resources. FAO Fisheries Technical Approach Paper 335:143.

[12] Government of India, 1990. Conservation of Mangroves in India, Ministry of Environment and Forests, New Delhi, August, 1990.

[13] Hassan, M. M. 1984. Soil formation in the recent deltaic region of Bangladesh. Bangladesh Journal of Soil Science 20:37-45.

[14] Hassan, M. M. 1988. Soil and Salinity of the Sundarbans in relation to top dying, regeneration and survival of Sundri. UPR of Bangladesh Forest Research Institute, Chittagong: 9.

[15] Hassan, M. M.; Mazumder, A. H.; Islam, A. T. M. N. and Hossain, A.T. M. E. 1990. Soil, hydrology and salinity of Sundarbans in relation to top dying, regeneration and survival of Sundri (Heritiera fomes) trees. In: Rahaman, M. A.; Khandakar, K.; Ahmed, F.U. and Ali, M.O. (Eds.). Proceedings of the Seminar on Top Dying of Sundri (Heritiera fomes) Trees. Bangladesh Agricultural Research Council, Dhaka: 1-

[16] Howlader, A. S. 1973. Report on the Preliminary investigation of Probable causes of Top-Dying, Regeneration and Survival of Sundri. Unpublished Report, BFRI, Chittagong, 9 pp.

[17] Imam, S. A. 1982. The Sundarbans and its future. In: proceedings of the Second Bangladesh National Conference on Forestry, Dhaka, Bangladesh, p.19-24.

[18] King, M. (1995). Fisheries Biology, Assessment and Management. Oxford: Fishing News Books.

[19] Landsberg, J. J. and Gower, S.T. 1997. Applications of Physiological ecology to Forest management. Academic Press, San Diego, CA, USA.
[20] Miller, J.R. (1981). Irreversible land use and the preservation of endangered species. Journal Environmental Economics and Management, 8, 19-26.

[21] Naskar, K. and Mandal, R. 1999. Ecology and Biodiversity of Indian Mangroves, Publishing House, New Delhi, India, Volume, I \& II, p.21.

[22] Rahman, M.A. 2003. Genetic Approach to mitigate the top Dying Problem of Heritiera fomes in the Mangrove Forests, Khulna University, Bangladesh, 87pp.

[23] Rahman, M.A. 2003. Mid-term Report on Top Dying of Sundri (Heritiera fomes) and Its Management in the Sundarbans Biodiversity Conservation Project, Khulna.109pp.

[24] Saha U. K; Rahman, A. F. M; Islam, M. S; and Khan, M. S. 1991. Optimizing fertilizer rate for mustard in calcareous dark grey flood plain soil of Bangladesh,

[25] Siddiqi, N. A. 2001. Mangrove Forestry in Bangladesh; Institute of Forestry and Environmental Science, University of Chittagong, Chittagong, p.201.

[26] Snedakar, S .C. 1984. General Ecology: Resource Utilization Potential for the Bangladesh, Dhaka, Bangladesh: 31 .

[27] Snedaker, S.C. 1977. General Ecology and Resource Utilization Potential of the Sundarbans, FAO Report No.Fo:TCP/BGD/2309 (MF) W/R, 28 prepared for the Government of Bangladesh, Dhaka: 31.

[28] Sokal, R.R. and Rohlf, F.J. (1981). Biometry. San Francisco, w.H. Freeman.

[29] Tamang, K. M. 1993. Wildlife Management Plan for the Sundarbans Reserved Forest. Integrated Resource Development of the Sundarbans Reserve Forest. UNDP/FAO, $\mathrm{BGD} / 84 / 056$, Khulna, Bangladesh.

[30] Thom, B.G.1982. Mangrove ecology- a geo-morphological perspective. 1982, p.3-17.

[31] Tiner, R. W; J R. (1984). Wetlands of the United States: Current Status and Recent Trends. Newton Corner, Massachusetts: U.S. Fish and Wildlife Service, Habitat Resources.

[32] UN-ESCAP, 1987. Final Report: Volume 2. Coastal environment management plan for Bangladesh. Bangkok, Thailand.

[33] UN-ESCAP, 1988. Coastal environment management plan for Bangladesh. Bangkok, Thailand: 7-34. 